\title{
Dualidad en la aljama. Propietarios de tierra y hombres de negocio musulmanes. El caso de la comarca valenciana de El Comtat (segunda mitad del siglo $\mathrm{Xv})^{1}$
}

\section{Duality in the Aljama. Muslim Landowners and Businessmen. The Case of Valencian Region «El Comtat» (Second Half of $15^{\text {th }}$ Century)}

\author{
José Antonio LLIBRER ESCRIG \\ Universitat de València \\ J.Antonio.Llibrer@uv.es
}

Recibido: 28 de abril de 2014

Aceptado: 5 de julio de 2014

\begin{abstract}
RESUMEN:
El presente trabajo pretende estudiar las diferencias socioeconómicas que se generaron en el seno de las aljamas musulmanas valencianas durante el siglo XV. A diferencia de lo que frecuentemente ha mostrado la historiografía, las comunidades islámicas rurales no eran grupos homogéneos de campesinos sin tierras, sino que había importantes jerarquías en su interior. Tomando como ejemplo el caso de la comarca de El Comtat, en la zona centro-sur del antiguo reino de Valencia, analizamos la dualidad social y económica de las aljamas a través del estudio del mercado de la tierra y del mercado de productos agrícolas. Todo ello nos permite descubrir una elite musulmana de propietarios y hombres de negocio que pocas veces muestran las fuentes.
\end{abstract}

Palabras clave: comunidades musulmanas, siglo XV, dualidad social, mercado de la tierra, élite rural, Reino de Valencia, El Comtat.

\begin{abstract}
:
This article studies the socioeconomic differences inside Muslim aljamas in the Kingdom of Valencia during the second half of the fifteenth century. Islamic communities were not homogeneous like historiography has shown. In these rural communities there were not only one group of landless farmers, there were also others social differences inside. With the example of «El Comtat», southern interior region of Valencia, we explain how the social and economic duality was born in the Muslim aljamas through the study of land market and agricultural products sales, so we can research directly the process of consolidation of the Muslim rural elites with peasant landowners and Businessmen.

Keywords: Muslim communities, $15^{\text {th }}$ century, social duality, land market, rural elite, Kingdom of Valencia, El Comtat.
\end{abstract}

SUMARIO: 1. Descubriendo las aljamas, 2. Un método y un espacio de análisis, 3. Actividades económicas: trabajar y «poseer» la tierra, 4. La aljama, un espacio plural: dualismos socioeconómicos como conclusion, 5. Apéndice.

\footnotetext{
${ }^{1}$ El presente trabajo se integra en el proyecto de investigación «Identidades urbanas Corona de Aragón-Italia: redes económicas, estructuras institucionales, funciones políticas (siglos XIV-XV)», con referencia HAR2011-28861, financiado por el Ministerio de Ciencia e Innovación (2012-2014), y dirigido por el prof. Paulino Iradiel Murugarren, catedrático del Dept. d’Història Medieval de la Universitat de València.
} 


\section{DESCUBRIENDO LAS ALJAMAS}

Hace unos pocos años, Mark Meyerson, uno de los mayores conocedores del mundo musulmán valenciano bajomedieval, reclamaba una nueva formulación, un nuevo enfoque, para los estudios del colectivo mudéjar. Indicaba la necesidad de un nuevo análisis «que considere a los mudéjares valencianos sujetos de su propia historia, verdaderos agentes en lugar de simples objetos del abuso cristiano», un análisis que además preste más atención a su propia reproducción social y cultural, al cultivo de su identidad islámica e incluso a sus propias estrategias y actividades económicas ${ }^{2}$. El autor recuerda además que las comunidades musulmanas, las aljamas, no dejaron nunca, ni bajo dominio cristiano, de establecer procesos de jerarquización interna, de establecer en definitiva un orden jerárquico socioeconómico propio, y paralelo -añadiríamos nosotros- al que al mismo tiempo se producía en las comunidades cristianas. Es cierto que numerosos investigadores han llevado a cabo estudios que, como reclamaba Meyerson, se introducen en los colectivos musulmanes para analizar desde su propia especificidad las relaciones y actividades que desarrollan, pero prácticamente todos ellos se han centrado en ámbito urbano, en grandes ciudades con poderosas y dinámicas morerías que generaban importantes grupos y familias islámicas de poder, y grupos y familias emprendedoras que llegaban a gestionar e incluso a dominar la política y buena parte de la actividad económica de estas importantes morerías ${ }^{3}$.

\footnotetext{
${ }^{2}$ MEYERSON, Mark, “Un reino de contradicciones: Valencia, 1391-1526”, en Revista d'Història Medieval 12 (2003), 11-30, esp. 17-18.

${ }^{3}$ En ámbito de la Corona de Aragón, que es el que ahora nos ocupa, deben destacarse, por una parte, los trabajos de Manuel Ruzafa sobre el colectivo musulmán de la ciudad de Valencia, RUZAFA, Manuel, Patrimonio y estructuras familiares en la morería de Valencia (1370-1500), Tesis doctoral inédita, Universitat de València, 1988; Id., "Los mudéjares en el desarrollo mercantil valenciano del Cuatrocientos", en Revista d'Història Medieval 2 (1991), 179-192; Id., "Élites valencianas y minorías sociales: la élite mudéjar y sus actividades (1370-1500)", en Revista d'Història Medieval 11 (2000),163-187. También los trabajos del mismo Meyerson, sobre todo su monografía, Els musulmans de València en l'època de Ferran i Isabel. Entre la coexistència i la croada, València, 1994; Id., "El precedente mudéjar: presiones aculturadoras y conflictos bajomedievales", en Entre tierra y fe. Los musulmanes en el reino cristiano de Valencia (1238-1609), R. Benítez, J.V. García Marsilla, N. Piqueras (coords.) (2009) 73-86. También sobre la ciudad de Xàtiva, O’CONNOR, Isabel, A Forgotten Community: The Mudejar Aljama of Xativa, 1240-1327, Leiden 2002. Es además destacable el amplio trabajo llevado a cabo por Germán Navarro, que se ha dedicado desde hace algunos años a desentrañar grupos, élites y familias de las más importantes aljamas aragonesas, pero también de las de ámbito rural, NAVARRO, Germán, Los mudéjares de Teruel y Albarracín. Familia, trabajo y riqueza en la Edad Media, Teruel, 2003; Id., "Por un estudio prosopográfico y genealógico de los mudéjares de Aragón en la Edad Media: las tierras turolenses y dos ejemplos concretos del Valle del Ebro (Alborge y Codo)”, en IX Simposio Internacional de Mudejarismo, Teruel (2004), 61-89. Específicamente, sobre la actividad mercantil de este colectivo, que nos interesa en el presente trabajo, CISCAR PALLARÉS, Eugenio, “Otras actividades económicas: el comercio”, en Entre tierra y fe..., 249-266; y en relación a esta área, SOLER MILLA, Leonardo, "Especulación mercantil en las aljamas mudéjares rurales del sur del reino de Valencia (siglo XV)”, en Medievalismo 17 (2007), 215-245.
} 
El ejemplo de los Xupió es no sólo el más significativo, sino además el mejor conocido gracias a los trabajos de Manuel Ruzafa. Los miembros de este linaje no sólo alcanzaron el nivel más alto de la jerarquía social y del poder interno de la morería de la ciudad de Valencia, siendo durante años jurados, adelantados y colectores de la aljama, sino que alternaron actividades artesanales (producción y tintado de paños) y mercantiles con el desempeño de todo tipo de cargos en el poder urbano e incluso en la administración del propio reino, llegado a ser traductores oficiales de la Bailía General -la institución foral valenciana encargada de la hacienda real- o llevando a cabo responsabilidades en su gestión administrativa -siempre atentos a cubrir la necesidades financieras de las mermadas arcas del monarca-, o también participando activamente en el arrendamiento de impuestos generales e incluso en la titularidad de algunos señoríos, comportándose como auténtica clase dirigente. Alí Xupió, el miembro más destacado de este ilustre linaje islámico, fue uno de los pocos mudéjares valencianos que recibió el tratamiento de En (título de cortesía catalán equivalente al don o señor castellano) como muestra de fama, respecto y de honorabilidad, objetivo que buscaban con ahínco los grandes grupos emprendedores urbanos, grandes notarios, mercaderes y hombres de negocio; su prestigio social le permitió incluso trabar amistad y negocios con los poderosos dirigentes cristianos, y entre ellos el mismísimo rey Alfonso V el Magnánimo ${ }^{4}$.

El ejempo de los Xupió, y algunos otros no tan destacados, nos muestran no sólo la solidez de estos linajes privilegiados, sobre todo nos recuerdan que estos colectivos musulmanes se mantuvieron fieles a su propia identidad y a su tradición. Pensemos además, y esto es tal vez lo más importante, que nunca manifestaron deseos de emigrar a tierras musulmanas aunque disponían -como los Xupió y como muchas otras familias mudéjares valencianas- de permisos reales para hacerlo, tampoco desearon cambiar su status de musulmanes adoptando la religión cristiana dominante, entendiendo que podían actuar en el mundo de los negocios, de las finanzas, del lucro, de la riqueza, desde su propia condición islámica y, sobre todo, entendieron que podían alcanzar el prestigio y la honorabilidad social desde esa misma condición religiosa y cultural.

En efecto, las fuentes valencianas de época bajomedieval, sobre todo de los siglos XIV y XV, y tanto públicas como privadas, están repletas de ejemplos de la constante interacción social y económica entre cristianos y musulmanes, incluso de evidencias de cooperación en todos los ámbitos productivos: en la agricultura, en el mundo artesanal y en los negocios mercantiles de ámbito urbano, pero también -y aquí es donde nosotros queremos incidir- en ámbito rural, en las pequeñas comunidades campesinas del interior, que escapaban a la influencia de las grandes rutas mercantiles, de las re-

\footnotetext{
${ }^{4}$ RUZAFA, Manuel, "Els orígens d’una família de mercaders mudèjars al segle XV: Çaat Ripoll (1381-1422)”, en Afers 7 (1989),169-189, e Id., “Alí Xupió, senyor de la moreria de València”, en L'univers dels prohoms, Valencia (1995), 137-173. Más recientemente, Id., "La familia Xupió en la morería de Valencia (1362-1463)”, en Biografías mudéjares. La experiencia de ser minoría: biografías mudéjares en la España cristiana, A. Echevarría (coord.) (2008), 233-290.
} 
des de los grandes hombre de negocio e incluso de las grandes empresas y compañías urbanas. También en estos pequeños espacios rurales, en estas villas que pocas veces alcanzaban el millar de vecinos y en sus aljamas equivalentes, se gestó un sector emprendedor con la dimensión de su propia escala local y comarcal. En efecto, la documentación adecuadamente estudiada y analizada nos muestra el destacado papel de muchas familias musulmanas, de auténticos hombres de negocio mudéjares que llegaban a intervenir en importantes mercados como el de numerosos productos agrícolas -el aceite es especialmente importante, como veremos-, lanas o ganado. Estos auténticos agentes mercantiles islámicos circulaban por un amplio territorio supracomarcal, llevando a cabo las gestiones necesarias para sus negocios e interactuando con otros colectivos con la normalidad que frecuentemente la historiografía nos había negado. El trabajo que ahora presentamos pretende ser una pequeña contribución no sólo a este objetivo básico y fundamental de recuperación, sino también pretende ilustrar cómo en ámbito rural, estos grupos desarrollaron una importante función productiva y mercantil, y un activo papel en el mercado de la tierra, accediendo directamente a los inmuebles rurales o a los arrendamientos de todo tipo de parcelas incluso de instalaciones o medios de producción tan trascendentes en la vida campesina como molinos, almazaras de aceite, hostales, carnicerías...

A lo largo de estas páginas veremos, como nos han mostrado las fuentes consultadas de algunas villas interiores del País Valenciano, a musulmanes que compran y venden parcelas de tierra con toda normalidad, que distribuyen aceite en grandes cantidades por amplias regiones y que desarrollan importantes actividades manufactureras. Observamos y descubrimos así a estos auténticos empresarios y hombres de negocio del Islam que viven en zonas rurales e incluso en pequeñas alquerías, y que abren nuevas vías de acción y negocio con sus propias particularidades, y explotando sus propias potencialidades.

\section{UN MÉTODO Y UN ESPACIO DE ANÁLISIS}

El último día de octubre de 1471, Alí Rufá, musulmán vecino de la morería de Cocentaina -pequeña villa de la comarca del Comtat, en el área centro-sur del interior valenciano- compra el dominio directo una casa almazara para la elaboración de aceite de oliva, a Bernat del Grado, labrador vecino de la misma villa. El inmueble contiene en realidad no una sino dos almazaras, es decir, dos instalaciones para el triturado de la aceituna (dos rotlos e dos bigues), e incluye además un patio exterior contiguo. Todo ello hace que el precio que exige el vendedor sea elevado, 1.200 sueldos, lo que obliga a Rufá a venderle a su vecino dos parcelas de olivar para pagar tan elevada cantidad 5 . Pero tal vez lo más interesante del negocio de Rufá es que

\footnotetext{
${ }^{5}$ Es difícil determinar el valor de tal cantidad sin conocer ampliamente el sistema monetario valenciano y el conjunto de valores que a éste se asignaba. El «sueldo» (sou en catalán), base de la moneda de cuenta, equivalía a 12 «dineros» (diners); mientras una «libra» (lliura) suponía el valor de
} 
las almazaras que adquiere son francas, es decir, libres de cualquier imposición o renta, pero que tiempo atrás habían sido cedidas en arrendamiento a Çaat Roget, otro musulmán de la misma morería de Cocentaina ${ }^{6}$. De este modo Rufá se convierte en el señor de Roget, quien anualmente pagará a Rufá -como propietario del dominio directo del inmueble- el censo enfitéutico acordado. Además, y es dato importante, las almazaras no se encuentran en el interior del espacio de la morería, sino en uno de los barrios cristianos más dinámicos, donde había otras almazaras de propiedad cristiana, el Pla de la Font ${ }^{7}$.

Prácticamente en un mes, Acén Citbón, otro musulmán contestano, acude a la mesa del mismo notario para llevar a cabo idéntico negocio. Citbón compra una almazara (con su patio y granero para la aceituna) a Francesc Ripoll, un importante y activo artesano pañero de Cocentaina, por un precio de 500 sueldos. En este caso, el precio es menor dado que la venta corresponde únicamente al dominio útil del inmueble, siendo el dominio directo propiedad de un beneficiado de la parroquia de Cocentaina, y a quien Citbón deberá pagar anualmente un censo enfitéutico de 2 sueldos y 6 dineros ${ }^{8}$. La dedicación a la producción y venta de aceite será, en efecto, uno de los negocios de Citbón, como veremos años después por la adquisición y arrendamiento de diversas parcelas de olivar en la zona, según documentamos en otros protocolos notariales.

También Çaat Borix, musulmán de la misma morería que aparece siempre ante notario como tendero, se interesará por el mismo lucrativo negocio del aceite. No olvidemos que el aceite, a parte de las necesarias utilidades domésticas de cocina e iluminación, era una materia prima básica para numerosas actividades artesanales, como la producción de jabón o, sobre todo, la elaboración de paños de lana, actividad esta última de gran importancia en estas comarcas del interior ${ }^{9}$. El tendero Borix, toma en arrendamiento una almazara por un año, a cambio de un pago en especie de 50 arrobas de aceite (lo que suponía la nada despreciable cantidad de 607 litros, y para cuya producción necesitaba unos $3.000 \mathrm{~kg}$ de aceitunas) ${ }^{10}$.

Pero no sólo en el mercado de aceite se implicaban los mudéjares más activos y emprendedores de estas zonas del interior valenciano. En 1473, Çaat Cabe, tendero

20 sueldos. Recordemos simplemente, a modo de sencilla relación comparativa, que el jornal de un trabajador con grado de oficial era de unos 2 sueldos y 6 dineros, mientras el de un aprendiz era alrededor un sueldo diario.

${ }^{6}$ La transcripción de los antropónimos respeta las formas que aporta la documentación.

${ }^{7}$ La referencia es del protocolo del notario de Cocentaina Miquel Pérez, en el Archivo Municipal de Cocentaina (AMC), Sección Protocolos, M-42 (1471-X-31).

${ }^{8}$ AMC, Sección Protocolos, M-42 (1471-XII-13).

${ }^{9}$ Sobre la destacada producción pañera en la villa de Cocentaina y su comarca, LLIBRER, José Antonio, Los orígenes de la industria de la lana en la baja Edad Media, Valencia 2007, e Id., Industria textil y desarrollo regional: la Vall d'Albaida y el Comtat en el siglo XV, Tesis doctoral inédita, Universitat de València 2010.

${ }^{10}$ Archivo de Protocolos del Colegio del Corpus Christi o del Patriarca, de Valencia (APPV), 23.821, notario Guillem Peris (1498-VII-4). 
vecino de la alquería de Benufit, tomó en arrendamiento el molino harinero -con una muela- de Joan de Calatayud, poderoso comerciante de paños de Cocentaina. El arrendamiento era por un solo año, pero Cabe debía pagar un elevado alquiler de 660 sueldos, lo que implicaba en el fondo la solvencia de Cabe. Pocos años después encontramos otro musulmán, vecino de una pequeña alquería, arrendando otro molino harinero, y desembolsando una importante cantidad de capital: se trata ahora de Axer Fat, vecino de Alcosseret, que toma en arriendo por un año el molino harinero del señor de Planes, Bernat Catalá, que cuenta con dos muelas, por 810 sueldos ${ }^{11}$.

Otros sectores manufactueros tampoco escapaban al interés del colectivo mudéjar, lo que de nuevo nos remite al carácter emprendedor de muchos de sus miembros. Ayet Cudori, de Cocentaina, toma en arrendamiento al mismo conde de Cocentaina, su horno de cocer cerámica, a cambio de entregarle la mitad de la obra de cada una de las cocciones que Cudori realice ${ }^{12}$.

Podríamos sin duda ir multiplicando los ejemplos de esta actuación destacada y emprendedora de muchos musulmanes de las aljamas rurales valencianas en estas comarcas, pero más allá de la acumulación de noticias documentales que podrían resultar interesantes pero también dispersas, se impone la necesidad de aplicar un coherente método de análisis que permita, más allá de las noticias y los detalles que ofrecen los documentos, acercarnos a las empresas, a las trayectorias y al conjunto de estrategias que llevaban a cabo estos musulmanes más activos. Nos referimos sin duda al método prosopográfico, que mediante la búsqueda y ordenación de las noticias de cada individuo utilizando y contrastando fuentes diversas, nos permite reconstruir el curriculum, el conjunto general de actividades, en el plano económico pero también sociofamiliar, que desarrollaba cada uno. Efectivamente, es a partir de muchos documentos de naturaleza en ocasiones heterogénea desde donde el historiador trata de dibujar la personalidad social y económica de los sujetos. En una sociedad medieval compleja y profundamente articulada, y con importantes diferencias regionales, la reconstrucción de la fisonomía de cada sujeto dentro de sus espacios y su comunidad posibilitará la interpretación y la explicación de procesos sociales y de actividades económicas ${ }^{13}$.

El análisis prosopográfico permite no sólo establecer perfiles sociales comunes y repetidos, además posibilita destacar las actuaciones excepcionales dentro de los

${ }^{11}$ APPV, 23.805, notario Guillem Peris (1480-I-4).

${ }^{12}$ APPV, 23.818, notario Guillem Peris (1495-IV-13).

${ }^{13}$ Como trabajo de referencia, que incluye bibliografía básica, NARBONA, Rafael, "El método prosopográfico y el estudio de las élites de poder bajomedievales”, en El estado de la Baja Edad Media: nuevas perspectivas metodológicas, Universidad de Zaragoza (1999), 31-49. Sobre la aplicación prosopográfica al colectivo mudéjar, deben destacarse, junto a los trabajos ya citados de Mark Meyerson, Manuel Ruzafa o Germán Navarro, los de LOPES DE BARROS, Filomena, "Las élites mudéjares del reino portugués”, en Biografías mudéjares..., 101-132; o los de MOLÉNAT, Jean Pierre, "L’élite mudéjare de Tolède aux XIVe et XVe siècle. Alfaquís, alcaldes et alcaldes mayores de moros", en Liber Largitorius. Études d'histoire médiévales offertes à Pierre Toubert par ses élèves, D. Barthélemy y J.-M. Martin (Eds.) (2003) 559-577. 
grupos y de un conjunto social dado. Y es por ello que el método prosopográfico resulta especialmente interesante aplicado al colectivo mudéjar y en un ámbito perfectamente acotado como es una pequeña comunidad-aljama rural. La base del presente estudio ha sido precisamente la aplicación de este método de análisis en una pequeña comunidad islámica rural, la de la villa de Cocentaina durante la segunda mitad del siglo XV, mediante la elaboración de un censo prosopográfico de los habitantes de su aljama y de otras comunidades vecinas -en ocasiones pequeñas alquerías- que mantenían con ella estrechas relaciones socioeconómicas. El resultado ha sido un interesante censo de 131 musulmanes, la mayoría residentes en la aljama contestana, para un ajustado periodo que va de 1470 a 1505 (vid. Apéndice). Así, la muestra no sólo permite una aproximación al interior de la aljama de Cocentaina, a sus familias y a sus diferencias sociales y económicas, también a las relaciones que éstas llevan a cabo, primero, con sus vecinos cristianos, con quienes desarrollan todo tipo de actividades y negocios, como veremos, y en segundo lugar con musulmanes de otras aljamas cercanas. De hecho, el acercamiento a las familias de la comunidad islámica de Cocentaina nos ha permitido conocer otras muchas pequeñas alquerías cercanas que prácticamente no han dejado rastro en la documentación. Musulmanes de Muro o de Fraga, de Catamarruc, Almudaina o Benilloba, pequeñas aljamas de pocas decenas de casas, situadas a menos de 10 kilómetros de Cocentaina, pero también otras algo más alejadas como las de la Vall de Seta o la Vall de Gallinera.

La reconstrucción prosopográfica nos permite así también un acercamiento espacial a estas comarcas y a estas humildes aljamas prácticamente desconocidas; lo que en el fondo significa -y éste es otro de nuestros objetivos-, sacar a la luz trabajos y negocios de los grupos mudéjares en ámbito rural, de zonas alejadas de las grandes ciudades y villas, y casi aisladas, pero paradójicamente muy activas y con importantes operaciones económicas de trascendencia comarcal, como intentaremos ver a continuación.

Pero, ¿por qué la elección de esta zona del centro-sur valenciano? ¿Por qué la comarca del Comtat y no otra? ¿Por qué la aljama de Cocentaina y sus comunidades vecinas? Desde hace unos años, numerosos estudios estaban demostrando la vitalidad económica de esta área del centro-sur del País Valenciano, centrada en tres comarcas históricas, la Vall d'Albaida, l'Alcoià y el Comtat ${ }^{14}$. Sus principales villas llevaron a cabo durante el siglo XV, y especialmente su segunda mitad, intensos procesos de desarrollo de las actividades industriales y mercantiles, sobre todo vertebradas a través de la producción manufacturera del sector textil. La producción y

${ }^{14}$ LLIBRER, José Antonio y NAVARRO, Germán "Indústria tèxtil del món rural: La Vall d'Albaida i El Comtat a les darreries del segle XV”, en Almaig. Estudis i Documents 8 (1991)17-23; IGUAL, David, NAVARRO, Germán, LLIBRER, José Antonio, "Materias primas y manufacturas textiles en las aljamas rurales valencianas de la Baja Edad Media”, en VI Simposio Internacional de Mudejarismo (1994) 311-327; MIRA, Antonio, Entre la renta y el impuesto. Fiscalidad, finanzas y crecimiento económico en las villas reales del sur valenciano (siglos XIV-XVI), Valencia, PUV 2005. 
distribución de paños de lana, y también de seda, entre todo el conjunto del centro y especialmente el sur del reino, convirtió a villas como Ontinyent, Alcoi o Cocentaina, en pequeños burgos poblados de artesanos y mercaderes que se ocupaban de todas las intensas fases de producción de los textiles: desde el abastecimiento de las materias primas, el tejido, el tundido, el abatanado y hasta el tintado, e incluso su distribución posterior en un amplio mercado que se extendía de Alzira a Elx, y de Denia a Biar, es decir, en todo el ámbito centro-sur valenciano. La industria textil -y el concepto industria está justificado tanto por la amplia especialización alcanzada como por los niveles de inversión de capital y sus formas de gestiónempleaba a miles de trabajadores, artesanos especializados (sólo entre 1470 y 1505 hemos llegado a documentar más 600 artesanos cristianos del textil, y de sectores asociados, en esta área), pero también jóvenes aprendices, mujeres y niños, que desde pequeños talleres familiares se ocupaban de muchas de las tareas del ciclo lanero que exigían menor especialización ${ }^{15}$. Pero si la documentación muestra una frenética actividad textil (el número de molinos batanes nos ha permitido calcular una producción anual en toda la zona de entre 8.000 y 10.000 paños), también resalta una intensa actividad mercantil centrada no sólo en la venta de estos bienes de consumo textiles, también en la adquisición de dos materias primas básicas: la lana y el aceite. ¿Y qué relación tiene la comunidad musulmana en todo este amplio e intenso proceso de desarrollo manufacturero? ¿Cómo interviene, si es que lo hace, en este rentable negocio textil? ¿Qué nos muestra de todo ello la documentación? Sin duda la función de los colectivos mudéjares no fue únicamente «clientelar» por el hecho de comprar o adquirir paños a los artesanos y mercaderes cristianos, fue más activa y compleja, en primer lugar porque llevaron a cabo una interesante función de control y mantenimiento de amplias cabañas ovinas que posibilitaban el abastecimiento de lanas a los talleres cristianos, también porque participaban de forma destacada en la producción de aceite y en su posterior distribución entre cristianos y musulmanes, lo que permitió, y es algo que también las fuentes destacan, la aparición de auténticos hombres de negocio musulmanes que supieron aprovechar también el amplio proceso de desarrollo de estas comarcas del interior, es decir, que entendieron desde el primer momento las posibilidades que se presentaban en un determinado contexto económico, y que no fueron ajenos a tal crecimiento

De esta forma, habiendo conocido bien esta producción textil y sus actores, era necesario un acercamiento a la comunidad mudéjar para analizar no sólo su relación con el mundo de los negocios y las actividades económicas de los cristianos, sino también sus propias estrategias y sus propios intereses, sus posibilidades y también las diferencias que éstas generaron en el seno de las aljamas, porque, no lo olvidemos, no todos los musulmanes supieron ni pudieron aprovechar de la misma manera las potencialidades que el contexto les presentaba.

${ }^{15}$ LLIBRER, José Antonio, Industria textil... 137-210. 
En primer lugar, y antes de entrar directamente en las aljamas, en sus actividades y negocios, es necesario un mínimo acercamiento demográfico para conocer bien de qué comunidades estamos hablando, cuáles son sus dimensiones aproximadas en relación a los grandes centros mudéjares ya conocidos y estudiados en ámbito valenciano. La humildad de nuestras pequeñas comunidades ya veremos que no excluye unas interesantes actividades productivas y mercantiles. En primer lugar, y centralizando buena parte de los negocios del área, destaca la aljama de Cocentaina, villa que como ya indicamos, disponía hacia la década de 1490, de unos 600 fuegos fiscales, de los que su morería supondría alrededor de 120-130, lo que sin duda indica la alta representatividad del análisis prosopográfico que hemos elaborado. Por otro lado, la aljama contestana se nos dibujaba como una de las más importantes de esta zona del mediodía valenciano, sin duda una de las más destacadas demográfica y económicamente del amplio espacio que iba de Xàtiva al valle de Elda, en lo que jurisdiccionalmente se conocía como la Governació dellà del Xúquer ${ }^{16}$. No olvidemos que las comarcas que nos ocupan, Vall d'Albaida, Alcoià y Comtat, disponían de un denso poblamiento mudéjar aunque ampliamente disperso, distribuido en una gran cantidad de pequeños centros o alquerías, de pocas decenas de casas, de manera que no se configuraron amplias aljamas urbanas. En realidad este particular sistema de poblamiento era en buena parte un reflejo de la herencia islámica pero también de lo que ocurría en ámbito cristiano, dado que, como hemos visto, tampoco en esta área se articuló ningún gran centro urbano sino un pequeño grupo de villas de tamaño medio, todas ellas con un número de fuegos -a lo largo del siglo XV- de entre 500-600 unidades, como las citadas Ontinyent, Bocairent, Albaida, Alcoi o Cocentaina ${ }^{17}$.

La importancia y centralidad de la aljama contestana hizo que generara un amplio espacio de influencia que se extendía en un radio de unos $15-20 \mathrm{~km}$ alrededor, sobre todo en dirección Este, hacia los valles interiores de Confrides, Guadalest y Gallinera, donde se acumulaban una gran cantidad de pequeñas alquerías islámicas. Son en efecto los datos prosopográficos los que nos indican este conjunto de relaciones socioeconómicas, de todos estos negocios que obligaban a los vecinos de aquellas pequeñas aljamas a acudir a Cocentaina para pasar ante la mesa de los notarios de la villa, y firmar sus acuerdos documentales. Musulmanes de Fraga, Muro, Catamarruc, Almudaina, Benilloba o de los Valles de Seta y Gallinera, veían en la

${ }^{16}$ FERRER I MALLOL, María Teresa, Els sarraïns de la Corona Catalano-Aragonesa en el segle XIV: segregació i discriminació, Barcelona, CSIC, 1987; Id., Les aljames sarraïnes de la Governació d'Oriola en el segle XIV, Barcelona, CSIC, 1988; y sobre todo, Id., "Las comunidades mudéjares de la Corona de Aragón en el siglo XV: la población”, en VIII Simposio Internacional de Mudejarismo, Teruel (2002), 27-153.

${ }^{17}$ Hacia 1493, Cocentaina contaba con unas 600 casas, Ontinyent tenía unas 580, Alcoi unas 410, mientras Albaida y Bocairent, de menor entidad, disponían, respectivamente, de 360 y 250. Sobre la estructura demográfica de la zona, y las fuentes utilizadas para su acercamiento cuantitativo, LLIBRER, José Antonio, Industria textil..., vol I, 150-178. 
capital del Comtat no sólo un amplio mercado para su abastecimiento sino también los estímulos económicos para incrementar sus posibilidades económicas. Y hasta tal punto las prosopografías nos confirman que esto es así que la propia aljama de Cocentaina irá incrementando constantemente su población gracias a la llegada y asentamiento de población mudéjar que procedía de las zonas cercanas citadas, y que buscaban consolidar sus negocios en la mayor morería del área ${ }^{18}$.

La alquería de Fraga, aljama más cercana a la capital del Comtat, situada casi a sus puertas (en la actualidad Fraga es ya un barrio de la ciudad), y perteneciente al monasterio de Sant Bernat de la ciudad de Valencia, contaba a finales del Cuatrocientos con unas 50 familias, que bien podían considerarse vecinas de la misma morería contestana, con lo que el colectivo mudéjar de Cocentaina estaría configurado por alrededor de 200 fuegos. Almudaina, a $5 \mathrm{~km}$ de la capital, Catamarruc a 12, y Alcosseret, a 15, eran otras pequeñas alquerías del área de influencia contestana que en ningún caso sobrepasaban las 20 casas $^{19}$. Algo más lejos, a unos $20 \mathrm{~km}$, el valle de Seta reunía unos 160 fuegos repartidos entre seis asentamientos: Balones, Quatretondeta, Benimassot, Tollos, Fageca i Famorca. El límite de influencia contestana se extendía, siempre hacia el Este, hasta los valles de Gallinera, Ebo y Laguar, que conjuntamente, y sumando todas sus pequeñas alquerías, suponían un total de 300 familias aproximadamente.

Resulta interesante destacar que estos valles interiores, de fuerte presencia y actividad mudéjar, eran una de las pocas zonas en todo el reino de Valencia que habían conservado de forma más intensa su identidad islámica. Siempre fueron consideradas por la autoridad real como muy representativas del colectivo mudéjar y de la cultura islámica, hasta el punto que se temía, durante buena parte aún del siglo XIV, por posibles revueltas contra la autoridad cristiana y bajo la alianza de Granada o Marruecos. En tan alta consideración se tenía estas zonas interiores, que sus representantes fueron con frecuencia convocados por orden real para presentarles diversas resoluciones legales que iban a afectar al colectivo musulmán del país, y que se preveían problemáticas ${ }^{20}$.

${ }^{18}$ En efecto, los análisis prosopográficos nos han permitido localizar numerosos musulmanes que son denominados por los notarios con el apelativo de «comorantes», es decir individuos inmigrantes y recientemente asentados en la villa. Son los casos de Azmet Alfarquí, comorans morarie Cocentayne, o el de Cilim Almenari, tendero; Azmet Axeix, herrero; Çaat Cabe, tendero (que llegó de Benufit); Borayham Cabe, carpintero; Cilim Cabe, también carpintero (que vino de la ciudad de Xàtiva), el mismo origen, sin duda, de los herreros Azmet y Çaat Xativí. Sus oficios nos indican el dinamismo de esta aljama. Vid. Apéndice prosopográfico final.

${ }^{19}$ Los datos de fuegos fiscales corresponden a diversos censos elaborados entre 1493 y 1510 para comprobar distintos derechos señoriales. Han sido publicados por GUINOT, Enric, "Senyoriu i reialenc al País Valencià”, en Congrés Internacional «Lluís de Santàngel i el seu temps», Valencia (1992) 185-202 y FERRER I MALLOL, María Teresa, “Las comunidades mudéjares...”, 64-133.

${ }^{20}$ Así sucedió, por ejemplo, en 1318, cuando las autoridades musulmanas de los valles de Gallinera y Laguar fueron convocadas, junto a sólo cinco comunidades mudéjares más de todo el reino, para que el gobernador de Valencia les explicara la reciente prohibición de la llamada a la oración, medida 
En total se nos dibuja un área de intenso poblamiento islámico, una de las zonas más importantes del reino, en cuyo centro se situaba la villa y aljama de Cocentaina, poderoso núcleo de actividades artesanales y mercantiles, que tendía a generar un ampio espacio de influencia, en clara dirección Este, formado por más de 600 familias. Esta pequeña región islámica se configuró como un importante mercado exclusivo para algunos musulmanes más emprendedores, se convirtió, en definitiva, en una oportunidad de negocio que unas pocas familias supieron explotar intentando promover las potencialidades que en mano de obra y en consumidores suponía esta amplia área del interior valenciano.

Conocido el espacio, y evaluados, en la medida que lo permiten las fuentes fiscales, los centros y aljamas que vertebraron el intenso poblamiento islámico de esta zona interior del reino, es momento de acercarnos a su interior, a sus actividades y a sus propias jerarquías socioeconómicas.

\section{ACTIVIDADES ECONÓMICAS: TRABAJAR Y «POSEER» LA TIERRA}

Se ha repetido con frecuencia que la actividad económica básica en las aljamas era el trabajo de la tierra. La afirmación es cierta, pero no deja de ocultar importantes particularidades que con frecuencia se olvidan en relación al mundo musulmán. La primera hace referencia a la supuesta categorización igualitaria, en el sentido de creer que todos los musulmanes eran campesinos de idéntico nivel y jerarquía, sin apreciar las numerosas diferencias que entre ellos se generaban; la segunda refiere a la propiedad de la tierra, y tiene relación con el aspecto anterior: ¿hasta qué punto los musulmanes accedieron a la propiedad de las parcelas? ¿Accedían y participaban del mercado de la tierra? ¿Adquirían parcelas alodiales o les estaba vetado este acceso?

Para intentar un acercamiento a todas estas cuestiones planteadas, comencemos de nuevo por las cifras y por los datos que nos ofrece nuestro análisis prosopográfico de la comunidad islámica. En relación a la dedicación agraria, del total de individuos censados (131), sólo el 29\% aparece en la documentación con un oficio específico, y no agrícola: hablamos en ese caso de artesanos, mercaderes u otros oficios del sector servicios. En total, hemos documentado para el citado periodo de 1470-1504: siete herreros, cuatro albarderos, tres cinteros, tres sastres, tres albañiles, tres productores de jabón, dos alfareros, dos carpinteros, dos yeseros, un calcetero, un panadero y un barbero; del sector mercantil hemos localizado hasta ocho individuos (cuatro tenderos, tres trajineros y un mercader), lo que nos habla ya de la importancia de estas actividades de intercambio en el seno de la aljama.

El resto de musulmanes censados, el 71\%, aparece sin ninguna denominación profesional, lo que nos lleva a pensar que se trata de agricultores o ganaderos, dato

que sin duda iba a generar enorme descontento entre los grupos islámicos del reino. Los detalles y su análisis en FERRER I MALLOL, María Teresa, Els sarraïns de la Corona Catalano-Aragonesa en el segle XIV: segregació i discriminació, Barcelona, CSIC, 1987, 89. 
confirmado no sólo por esta ausencia sino también por los negocios que en alguna ocasión llevan a cabo ante el notario. De estos primeros datos cabe destacar, por una parte, la importante diversidad profesional que se cuajaba dentro de las aljamas, donde un tercio de sus efectivos se dedicaba a otros sectores más allá de la tierra; por otra parte, sin entrar en posibles combinaciones sectoriales (en el sentido que un artesano podía dedicarse a tiempo parcial al trabajo de la tierra), entre los mudéjares era frecuente la ausencia de identidad sociolaboral agrícola, es decir, la mayoría de los labradores musulmanes pocas veces aparecía ante el notario como tal, aunque la tierra fuera la fuente básica de su mantenimiento ${ }^{21}$.

Lo cierto es que el trabajo de la tierra entre los musulmanes ha dejado poco rastro en la documentación: en ocasiones las compraventas de productos agrícolas o las adquisiciones de inmuebles rústicos nos permiten acercarnos a esta economía interior. Y estas dos tipologías documentales básicas, que nos facilitan cierto análisis cuantitativo ${ }^{22}$, nos servirán para realizar una reconstrucción de las actividades de las aljamas. En el periodo que va de 1470 a 1498, hemos llegado a localizar hasta 81 documentos notariales de compraventa de tierra, más otros cuatro de inmuebles urbanos $^{23}$, donde intervienen directamente musulmanes de nuestra zona de estudio, sobre todo de la aljama de Cocentaina y de sus alquerías más cercanas (Fraga, Alcudia, Almudaina y Muro) ${ }^{24}$. En total hemos llegado a conocer un conjunto de más de un centenar de parcelas, bancales o huertos que musulmanes de esta zona venden o adquieren, o toman en arrendamiento en sólo una veintena de años: concretamente

${ }^{21}$ Sobre las razones de esta ausencia, VICIANO, Pau, Els peus que calciguen la terra. Els llauradors del País Valencià a la fi de l'edat mitjana, Valencia 2013, 38-42.

${ }^{22}$ Recordemos que el historiador tiene la obligación de ofrecer datos cuantitativos para medir magnitudes y, de esa manera, poder llegar a conclusiones sustentadas y fiables. Entendemos así que la cuantificación es una de las tareas básicas del trabajo de investigación histórica. No es posible llegar a conclusiones contrastadas a través de métodos «impresionistas» de trabajo, es decir, a través de unos pocos ejemplos encontrados al azar en la documentación.

${ }^{23}$ Es normal que el número de compraventas de casas con la participación mudéjar sea escaso, por el hecho que las transacciones de estos inmuebles de la aljama entre musulmanes se resolverían sin pasar por el notario. Por el contrario, era cuando los musulmanes adquirían inmuebles fuera de la morería a propietarios cristianos, cuando se hacía necesario el recurso al documento notarial. En efecto, así ocurre con los ejemplos localizados: en 1481 Çaat Amic, de Cocentiana, compra a Mateu Oltra, pelaire de la misma villa, una casa franca por 480 sueldos; en 1488, Cilim Cabe vende el dominio útil de un obrador, situado en la plaza Mayor de la villa, al pelaire Joan Sancho, por 400 sueldos; Azmet Axeix, herrero contestano, compra una casa extramuros al hostalero Joan Llobregat, por 100 sueldos; Çaat Xativí compra en 1496 una vivienda en la morería a Joan Pérez de Requena, pelaire, por 90 sueldos. Todos los ejemplos en LLIBRER, José Antonio, Industria textil..., vol. II, 303-325.

${ }^{24}$ En realidad, y este dato es especialmente trascedente, la muestra no corresponde al periodo completo de 28 años, dado que no conservamos documentación notarial de todos ellos. No disponemos de información relativa a seis años $(1475,1476,1477,1478,1483$ y 1490), de modo que las transacciones documentadas implican sólo 21 años, lo que nos habla de la interesante actividad mudéjar en el mercado de la tierra, y a su vez concede a la muestra mayor rango de representatividad. Desde el punto de vista de la periodicidad anual, es la década de 1490 la que concentra en nuestra muestra mayor movimiento y actividad musulmana en el mercado inmobiliario con más de la mitad (62\%) de las transacciones. 
hablamos de 128 parcelas $^{25}$. La muestra puede parecer escasa a simple vista, pero por el contrario resulta altamente indicativa si pensamos que la morería de Cocentaina y sus alquerías más cercanas -que son las que intervienen en este mercadotenían una población estimada de unas 160-170 familias. Con todo, aunque se trata de un número limitado para un estudio estadístico amplio, es suficiente para observar la propiedad y el mercado inmobiliario en el que se implica el colectivo mudéjar, incluso para realizar un acercamiento a la práctica del crédito y a su capacidad económica. El número de actos documentales es además suficiente para reconstruir formas de actuación e incluso estrategias inmobiliarias del colectivo rural mudéjar.

Es interesante analizar qué relación proporcional supone este mercado con respecto al inmobiliario global que aparece en los protocolos de Cocentaina, esencialmente en los de Guillem Peris que supone la base de nuestra investigación. Sabemos que éste último trabajó en la villa entre 1469 y 1504, periodo durante el cual redactó un protocolo anual, aunque sólo conservamos un total de 30 libros; por otro lado, en un reciente artículo pendiente de publicación, hemos analizado con detalle el trabajo de este notario entre los años 1469 y 1487, y mediante una clasificación de sus actos documentales hemos contabilizado, para el periodo citado, un total de 173 compraventas de inmuebles rústicos, y 54 de inmuebles urbanos ${ }^{26}$. Esto nos indica que, siempre para el periodo 1470-1487, en el 23,69\% de las transacciones de inmuebles rústicos, y en el $3,7 \%$ de los urbanos, participaban los musulmanes de la zona.

Es cierto que en relación a la actividad cristiana, la mudéjar es limitada, pero sin duda este colectivo islámico actúa en el mercado de heredades, parcelas y huertos de forma directa y mucho más allá de lo testimonial, hasta permitirnos un interesante análisis de su actuación ${ }^{27}$. Debemos destacar además que su participación es marcadamente local, es decir, las familias musulmanas se interesan por las tierras de las zonas donde viven, de las áreas circundantes a sus aljamas y alquerías: el 95\% de los compradores y el 92\% de los vendedores islámicos son vecinos de estas mismas aljamas, de Cocentaina y de sus cercanas Fraga, Almudaida, Alcudia o Muro, ubicadas todas en un radio de unos $5 \mathrm{~km}$ alrededor de la morería más importante, Cocentaina. Como es lógico, esta potente aljama concentra la mayor parte de los compradores (60\%) y de los vendedores musulmanes (64\%). El resto de los porcentajes se reparten entre las vecinas alquerías citadas. Es testimonial la presencia de

${ }^{25}$ La fuente básica para estos datos es el conjunto de protocolos conservados de Cocentaina para la segunda mitad del siglo XV, y sobre todo los del notario Guillem Peris, que trabajó en esta villa y su comarca desde 1469 a 1504. Sobre estas fuentes, LLIBRER, José Antonio, Industria textil..., vol. I, 90-126.

${ }^{26}$ LLIBRER, José Antonio, “Els protocols de Guillem Peris. L'especialització artesanal d'un notari vilatà (segona meitat del segle XV)", en Estudis Històrics i Documents del Arxius de Protocols (en prensa).

${ }^{27}$ En los protocolos de Peris, la presencia musulmana es también intensa, suponía el $17 \%$ de los otorgantes documentales y el 5,61\% de los beneficiarios, en el periodo comentado. Todo ello no hace sino indicar el dinamismo que este colectivo islámico desempeñaba en la vida económica de esta zona interior, LLIBRER, José Antonio, “Els protocols de Guillem Peris”... (en prensa). 
compradores o vendedores de comunidades islámicas más alejadas (dos de Planes, uno de Albaida, otro de Orxeta, tres de Albacar). Los problemas legales de movilidad del colectivo musulmán dificultaban sin duda su intervención inmobiliaria más allá del ámbito local ${ }^{28}$.

Del análisis documental inmobiliario musulmán, la primera idea que trasluce es el amplio predominio de las transacciones de compraventa ante los contratos de arrendamiento: frente a los 80 actos de adquisición (incluyendo inmuebles rurales y urbanos), sólo hemos documentado cinco arrendamientos en todo el periodo. Es cierto que esta diferencia puede estar en relación con el carácter oral en el que se podían enmarcar algunos de los contratos de arrendamiento rurales, pero también es cierto que este primer dato tiende ya a cuestionar algunos de los tópicos asociados a la actividad agrícola mudéjar. Por ejemplo, el que aludía a su acceso a la tierra a través casi exclusivamente del arriendo, y por lo tanto su escasa capacidad y posibilidad para llegar al mercado de la tierra, y para detentar propiedad franca o alodial. El caso constestano confirma que los musulmanes accedían a este factor básico de producción también mediante el mercado, y no sólo a través de sistemas intrafamiliares de transmisión (que nos son desconocidos por la ausencia de fuentes islámicas propias). Es evidente que no disponemos de documentación para conocer el porcentaje de uno u otro sistema de acceso a la tierra (sistemas intrafamiliares de herencia y transmisión o mercado) por parte de las familias musulmanas, pero es claro que el mercado suponía una vía que hasta ahora no se había valorado lo suficiente para el colectivo mudéjar. Por otro lado, nuestra muestra nos permite confirmar que muchos musulmanes estaban en condiciones de adquirir inmuebles en el mercado, y que además en muchas ocasiones estas parcelas y casas adquiridas eran alodiales o francas. Finalmente, podemos afirmar incluso que la propiedad alodial no era una excepción dentro de las aljamas: resulta sorprendente destacar que el $50,68 \%$ de las parcelas localizadas en manos del colectivo mudéjar eran francas, mientras sólo el 36,98\% tenían algún tipo de censo asignado sobre el inmueble ${ }^{29}$. En definitiva, no era infrecuente que la comunidad islámica accediera al mercado inmobiliario local; y en el momento en que participaba de este mercado, lo hacía en buena medida para adquirir o poner en circulación parcelas alodiales.

A la hora de explicar esta importante particularidad de la tenencia fundiaria en esta zona, se nos plantea la cuestión clave de cuál es su origen. Es cierto que la propiedad franca et quitia estaba mucho más extendida en ámbito valenciano que en otras área peninsulares fruto de las particulares circunstancias postconquita, pero también es cierto que el concepto de libre o franco no implicaba total ausencia de

\footnotetext{
${ }^{28}$ Sobre estos problemas, TORRÓ, Josep, "Vivir como cristianos y pagar como moros. Genealogía medieval de la servidumbre morisca en el reino de Valencia”, en Revista de Historia Moderna 27 (2007), 11-40.

${ }^{29}$ Desconocemos el régimen de tenencia de un porcentaje de inmuebles localizados en manos de familias musulmanas (12,34\%), dado que el notario no aporta información alguna que nos permita deducirla.
} 
imposiciones sobre la tierra y su producción ${ }^{30}$. En una sociedad bajomedieval fuertemente jerarquizada y diversificada, la realidad ofrecía diferentes situaciones en ámbitos y regiones distintas. Así, entendemos que lo que ocurría en estas comunidades rurales del interior-sur y en sus aljamas, no tiene porqué ser extrapolable a otras zonas del reino, por ejemplo a lo que ocurría en las áreas circundantes a las grandes urbes, como en este caso la ciudad de Valencia y en su amplia plana irrigada -l'Horta-, donde la presencia islámica y lógicamente su propiedad de la tierra (y su participación en este mercado) era muy limitada, y donde la propiedad franca era prácticamente inexistente para este colectivo ${ }^{31}$. Sin embargo, conviene recordar que lo que la documentación nos muestra en estas comarcas del interior-sur define también a la comunidad musulmana y es una parte de su realidad, de una realidad que no dejaba de ser plural. Hablamos de una evidente dualidad, ya explicada y analizada por otros autores, dentro del grupo islámico. Dualidad que se vertebraba en el interior de las aljamas, entre un grupo de campesinos propietarios y otro formado por una gran cantidad de labradores sin tierras, que la documentación denominó con frecuencia «eixarics» o «exameces», que subsistían mediante el trabajo para otros propietarios ${ }^{32}$.

Otro rasgo fundamental, y en parte también novedoso, que hemos podido descubrir del análisis de las comunidades contestanas es el relativo a la calidad de la tierra a la que accedía el colectivo musulmán. De las más de cien parcelas en manos de estas familias, el 51\% eran de regadío, como se indicaba explícitamente en los documentos: quoddam troceum terre rigui, situm in termino iamdicte ville, in partita del Pla de la Font, plantatum moreris et aliorum arborum. Esta es la descripción

\footnotetext{
${ }^{30}$ Hablamos de diversas cargas y conceptos impositivos presentes en las aljamas como el almagram, la alfarda y otras, pagadas generalmente en metálico, y que eran calculadas en función de la calidad del suelo, la frecuencia del riego, los cultivos... En este sentido son fundamentales, TORRÓ, Josep, "Del almagram a las particiones de frutos. Las cargas agrarias en las aljamas musulmanas del reino de Valencia", en Los tributos de la tierra. Fiscalidad y agricultura en España (siglos XII-XX), R. VALLEJO y A. FURIÓ (coords) (2008), 185-222; también TORRÓ, Josep, “Vivir como cristianos...”, 11-30; y los trabajos de ABBOUD-HAGGAR, Soha, "Leyes musulmanas y fiscalidad mudéjar”, en Finanzas y fiscalidad municipal. V Congreso de Estudios Medievales, León (1997), 168-205; Id., "Precedentes andalusíes en la fiscalidad de las comunidades mudéjares”, en En la España Medieval 31 (2008), 475-512.

${ }^{31}$ En un amplio estudio del mercado de la tierra en las comarcas cercanas a la capital, desarrollado mediante una amplísima muestra de 602 transacciones documentadas entre 1401-1511, los autores únicamente localizan tres musulmanes como vendedores y siete como compradores, lo que supondría escasos porcentajes del 0,49\% y 1,16\%. FURIÓ, Antoni y MIRA, Antonio, "Le marché de la terre dans le Pays de Valence au bas Moyen Âge”, en Le marché de la terre au Moyen Âge, L. Ferrer y C. Wickham (dirs.) (2005), 573-623. En otra pequeña villa rural, La Pobla de Vallbona, vecina de varias comunidades musulmanas, y situada a una veintena de kilómetros de Valencia, la participación islámica en el mercado de la tierra también fue muy limitada (el 3,8\% de los compradores y el 6,6\% de los vendedores), BORDES, Josep y LLIBRER, Antoni, "La Pobla en época medieval”, en La Pobla de Vallbona: Historia, Arte y Geografía, J. Hermosilla (dir.) (2011), 40-63.

${ }^{32}$ Vid. TORRÓ, Josep, El naixement d'una colònia. Dominació i resistència a la frontera valenciana (1238-1276), Valencia 2006; también TORRÓ, Josep, “Vivir como cristianos...”; y VICIANO, Pau, Els peus que calciguen la terra..., 38-45.
} 
de la parcela que Bartomeu Vayello, hostalero de Cocentaina, vende a Alí Zampar, sarraceno morarie ville prefate, por un precio de 600 sueldos. Un año después, Mohomat Potot, agareno loci de Fraga, compra a Joan Cirera, pelaire contestano, tres bancales de tierra, situados en regadío -rigui-, por 900 sueldos; Çaat Palluix, agareno de Muro, compró a Bartomeu Maiques, pañero de Cocentaina, quoddam troceum terre rigui, ubicado en la huerta de Muro, por 370 sueldos; la parcela lindaba con otra de Yaye Cabe y con una tercera de Çaat Faquí ${ }^{33}$. En ocasiones se especificaba que tal parcela incluía su derecho al agua, e incluso las horas de riego que ésta tenía asignada semanalmente. En 1491, Cale Polopí, de la morería contestana, compra a Bernat Puig, agricultor de la villa, un trozo de tierra que contiene siete bancales, en regadío y con su derecho al agua:

Ego, Bernardus Puig, agricola, vicinus ville Cocentayne, de certa sciencia et consulte, cum hoc presenti publico instrumento, vendo vobis, Cale Polopi, agareno comoranti in moraria ville prefate de Cocentayna, presenti et vestris, quoddam troceum terre in se contingentem septem banqualia terra rigui, meum, aliquibus arboribus plantatum, situm et positum in termino ville de Cocentayna, in orta loci de Fraga, franchum, etc. Prout confrontatur cum terra michi, dicti venditoris, remanenti, cum terra dicti loci de Fraga et cum camino quo itur a Planes. Cum iure aque eidem pertinenti. Iamdictum itaque troceum terre cum septem banquals prout superius est confrontatum, limittatum et terminatum cum ingressibus et egressibus, arboribus, plantis, aquis, çequis ad rigandum etc. De quibus, etc. Et quibus, etc. Ad habendum, tenendum, etc. Exceptis, etc. Sich vobis, predicto Cale Polopi, presenti et vestris, vendo precio videlicet, centum octoaginta octo librarum monete regalium Valencie, quas omnes a vobis confiteor habuisse et recepisse ${ }^{34}$.

La transcripción casi completa del documento obedece lógicamente a las numerosas informaciones de interés que contiene: junto a las referencias ya citadas de su ubicación en la zona de huerta, los bancales de regadío y de su derecho al agua, se nos indica que los siete bancales son francos, y cuyo alto precio, los 3.760 sueldos, ha sido pagado en el momento de la realización de la venta. Encontramos también ejemplos en sentido contrario, es decir musulmanes que venden a cristianos: Mahomat y Azmet Faraig, hermanos agarenos residentes en Muro, venden a Guillem Sanç, agricultor de Cocentaina, cierta parcela franca de moreras y otros árboles, cum iure aque sibi pertinenti, situada en la huerta de Muro, y que linda con otra de Azmet Yillel y con la acequia; el precio de dicha parcela, 250 sueldos, es entregado por Sanç en metálico en el momento de la transacción ${ }^{35}$. También a través del arrendamiento llegaban los musulmanes a las parcelas e incluso heredades de regadío: en 1482, Abrahim Çagola, de Cocentaina, toma en arrendamiento una heredad de re-

${ }^{33}$ Las tres referencias, respectivamente, en APPV, 23.807, notario Guillem Peris (1482-II-20), 23.811 (1486-I-18), 23.813 (1488-III-7).

${ }^{34}$ APPV, 23.386, notario Guillem Peris (1491-XII-16).

${ }^{35}$ ARV, Sección Protocolos, núm 1.795, notario Guillem Peris (1474-VIII-8). 
gadío propiedad del mercader Bartomeu Bodí, quandam hereditatem meam rigui, sitam in termino de Cocentayne, por tiempo de un año, y 62 sueldos de censo ${ }^{36}$.

En otras ocasiones, el mismo notario llega a detallar incluso el horario semanal de riego que tiene asignada la propiedad de la parcela: en 1481, el pelaire contestano Bernat Figuerola vende a Abrahim Quachola, sarraceno comorante en la morería de la villa, quoddam troceum terre meum, plantatum diversorum generum arborum, cum six horeis aque de octo in octo diebus, franchum, valorado en 3.000 sueldos; la parcela linda con otra de Alí Aldán. Lo sorprendente es que éste último, Aldán, agareno de la Alcudia, compra el mismo día y al mismo vendedor, el citado pelaire Figuerola, una parcela también franca constituida por tres bancales de regadío, cum quattuor horeis aque de octo in octo diebus, que confronta con parcela de Alí Zampar; el precio en esta segunda transacción es de 2.400 sueldos $^{37}$.

Frente al ya comentado $51 \%$ de las parcelas de riego que estuvieron en manos de los musulmanes, el $28 \%$ son citadas y detalladas por el notario como de secano quoddam troceum terre sicani. Sólo un ejemplo interesante por sus características y las parcelas musulmanes de sus lindes: Abrahim Asquer y su esposa Fadela, agarenos de Cocentaina, venden a Pere Cebrià, pelaire vecino, cierta parcela franca en secano, sicani, plantatum certa pars pinari et alia pars terra campa, que afrontaba con parcelas de Mahomat Cale, alias el podador, y de Çaat Zampar. El mismo Cebrià compró pocos años después otra parcela franca de secano con higueras y almendros, esta vez a Mahomat Colotí y su esposa Fotay (quoddam trocum terre nostrum, sicani... franchum et quititum), por 240 sueldos ${ }^{38}$.

A pesar de los numerosos detalles que nos aparecen en las descripciones notariales, en ocasiones no se llega a indicar si las parcelas en circulación son de regadío o secano. Esto ocurre hasta en el 21\% de los casos, y tal vez por el conocimiento que entre ambas partes había de las partidas rurales y sus características. En algunos casos nos podríamos haber aventurado a asignar el tipo de parcela en función de la partida donde ésta estaba ubicada o en función de sus lindes (con alguna acequia o algún torrente), lo que hubiera supuesto elevar algunos puntos el porcentaje de parcelas de riego, pero hemos descartado tal posibilidad para evitar cualquier pequeña distorsión en los cálculos documentales. Con todo, parece evidente que los miembros del colectivo mudéjar tenían acceso a las rentables parcelas de regadío, y no estaban obligados a trabajar en exclusiva las tierras de peor calidad, en las partidas únicamente de secano o de zonas montañosas. En Cocentaina, Fraga, Muro o Almudaina, las compraventas de tierra, los arrendamientos y los lindes que se detallan en las escrituras notariales, nos muestran cómo cristianos y musulmanes compartían las mismas partidas, las zonas de riego y secano, con sus acequias, alji-

${ }^{36}$ APPV, 23.807, notario Guillem Peris (1482-IV-22). Çagola deberá pagar además el impuesto de la peita y una pensión censal que hay sobre dicha heredad.

${ }^{37}$ APPV, 23.806, notario Guillem Peris (1481-X-31). En ambos casos, los compradores Quachola y Aldán, cargan sendos censales para pagar una parte del precio de los inmuebles.

${ }^{38}$ APPV, 23.804, notario Guillem Peris (1479-I-16) y 23.809 (1484-IX-17). 
bes y caminos. De hecho, un vistazo a los lindes de las parcelas en juego, nos indican esta plural y amplia presencia de propietarios o arrendatarios islámicos: en el $37,5 \%$ de las parcelas, heredades y huertos de musulmanes, aparecen lindes con otras parcelas en manos de otros miembros de este colectivo. Si bien no podemos conocer completamente el régimen de tenencia de dichos inmuebles (propiedad alodial, enfitéutica u otro sistema), lo que resulta evidente es que el notario al describir las afrontaciones utiliza siempre expresiones asociadas a la propiedad: confrontatur cum terra Joannis de Ceralta, et cum terra Ali Aldan...; confrontatur cum terra Bartholomeo Cirera, et cum terra Ai Rufa...; confrontatur cum torrente de les Mans, cum olivario Bernardi Cirera, cum olivario Maymo Açet et cum cequia de la Alcudia; o también en catalán: així com afronten ab terra de la herència de Berenguer Mari, e ab terra de Çat Mazella...

Los huertos, estratégicos espacios de cultivo, también aparecen en manos de los musulmanes, son por ellos adquiridos y vendidos: hasta siete huertos hemos documentado en manos de familias islámicas, a los que deberíamos sumar cinco más localizados en los lindes de otras propiedades: en 1492, Fofayda, viuda de Çaat Mecli, y su hijo Azmet, comorantes en Cocentaina, venden a Garcia Roís de Mora, un huerto tapiado, quoddam ortum nostrum clausum de parietibus, situado en una interesante partida, la de los Huertos de la Morería, in partita vulgo dicta dels orts del magram morarie dicte ville, y que confronta con el camino de Penàguila, con el camino a la Huerta de los Agarenos (cum camino orte agarenorum) y con dos huertos de otros tantos musulmanes (cum orto Cilim Almenari et cum orto Maymo Rasconi et fratis eius) ${ }^{39}$. Azmet Alfaquí y su esposa, de la misma aljama, vendieron en 1487 su huerto -ortum nostrum tapiatum... franchum- a los hermanos Castelló, de Alcoi, por el elevado precio de 2.540 sueldos; el huerto lindaba con la casa de Azmet Aldán ${ }^{40}$. Alí Barbarroja, de la misma morería, vendió en 1493 su huerto, también con derecho al agua, pero situado en la partida del Terratge, y que lindaba con el huerto de Cilim Almenarí, por un precio de 600 sueldos $^{41}$. En definitiva, la riqueza de las descripciones notariales nos permite conocer hasta un centenar más de parcelas en manos de musulmanes, aunque sin conocer detalles de su régimen de tenencia.

Junto a la posibilidad o no de riego, otro factor clave en la tierra era su cultivo, que sin duda determinaba valores, inversiones y adquisiciones. Una mínima cuantificación de las 128 parcelas que han sido documentadas en algún momento en

${ }^{39}$ APPV, 23.815, notario Guillem Peris (1492-II-7). En el documento se especifica que el precio de 300 sueldos incluye el derecho al riego (cum iure aque eidem pertinenti in fonte morarie dicte). El valor tan ajustado del huerto tiene que ver, sin duda, con los censos que debe pagar, el almagram (tentum et obligatum dicto domino Comitti ad magram et servitute sarracenorum), pero sobre todo por un censal que se cargó sobre dicho inmueble, y que exige el pago anual de 33 sueldos y 4 dineros, y cuyo capital es de 400 sueldos.

${ }^{40}$ APPV, 23.812, notario Guillem Peris (1487-IV-28). El notario indica además que dicho huerto lindaba con la acequia de la morería, cum cequia generali morarie.

${ }^{41}$ APPV, 23.816, notario Guillem Peris (1493-VIII-2). A nivel impositivo, este huerto ofrece prácticamente idénticas características que el anterior. 
manos del colectivo islámico nos aporta datos de nuevo interesantes: la mitad de las piezas de tierra $(50,68 \%)$ en las que el notario nos indica el cultivo, eran de terra campa, denominación genérica que en ámbito valenciano definía el cereal. En cierto modo este predominio era equivalente al que se daba entre los cristianos, en relación a bases y costumbres alimentarias. Pero lo que realmente llama la atención es su interés por las tierras plantadas de olivar, que llegaron a suponer el 34,24\% de las parcelas que compraban o que ponían en circulación. Este interés estaba en relación lógicamente con el mercado de aceite en el que participaban, como veremos, de manera muy activa. La vid $(8,21 \%)$ o la morera $(6,84 \%)$, de estratégico interés mercantil, suponían menor número de parcelas pero nos hablan, junto a la higuera, el almendro o la pluralidad de los huertos (éstos últimos representaban el 6,84\%), de la amplitud de intereses del grupo islámico en sus actividades agrícolas. El predominio, por lo tanto, del cereal no excluía el interés en otros cultivos para los campesinos musulmanes.

Pero el análisis de la propiedad y de la intervención del colectivo islámico en el mercado de inmuebles debe completarse con un dato clave, el que refiere a la inversión, al valor de los inmuebles que se ponían en circulación, al capital que exigían estas adquisiciones para los musulmanes. En época bajomedieval, la asignación del precio de una parcela de tierra dependía de muy diversos factores, algunos externos y fácilmente observables (régimen de tenencia, censos, ubicación en regadío o secano, derecho al agua, cultivo, extensión, distancia al núcleo de población), otros estaban asociados a conceptos, no siempre cuantificables, relacionados con la situación de la propia economía familiar, con problemas de transmisión o herencia (matrimonio de hijos y donaciones asociadas), deudas contraídas o simple necesidad coyuntural de capital que exigía una venta rápida del inmuebles y por ello una asignación de precio no siempre lógica (o al menos desde nuestra lógica capitalista) $)^{42}$. En nuestro caso contestano contamos además con un importante handicap para analizar los precios de los inmuebles, y es la ausencia total en nuestras transacciones de la información sobre la extensión de las parcelas. En ningún caso, ni tampoco en las compraventas donde intervienen únicamente cristianos, el notario indica los detalles de la superficie de las parcelas o bancales. Siempre se describe la parcela o el lote a vender con la denominación genérica de «trozo» de tierra (tros, troceum), o directamente en referencia a su cultivo («cierta viña», «cierto olivar»). No podemos, por tanto, unificar los precios en relación a una medida de superficie, pero sí al menos acercarnos a sus valores y a las inversiones de capital que la tierra exigía, inversiones que nos permitirán aportar cifras indicativas por el hecho que abarcamos un periodo de tiempo limitado, sólo los 28 años de 1470 a 1498.

\footnotetext{
${ }^{42}$ Para entender la complejidad de los precios en el mercado de la tierra bajomedieval, FURIÓ, Antoni, "El mercado de la tierra en el País Valenciano a finales de la Edad Media”, en Hispania LV/3 (1995), 887-919, y también FURIÓ, Antoni y MIRA, Antonio, “Le marché de la terre...”, 591-623.
} 
En general, si contabilizamos el valor de las tierra adquiridas por musulmanes en esos años, y en los documentos conservados (hemos excluido lógicamente los arrendamientos), la inversión media que debían encarar las familias islámicas para acceder a esos inmuebles rústicos era de casi mil sueldos, en concreto de 946 sueldos. Somos conscientes de la diversidad de características que planteaba cada parcela (tenencia, regadío, secano, cultivo, etc.), pero lo cierto es que la cifra resulta elevada, muy elevada si pensamos que refiere únicamente a los precios de las parcelas adquiridas por este colectivo. El valor máximo registrado, es decir la inversión máxima de capital, es de 3.760 sueldos, mientras el precio mínimo pagado por una parcela es de 70 sueldos. Tal vez estos datos no aporten demasiado, pero sí lo harán si indicamos que en algo más de la mitad de las adquisiciones (51,35\%), los musulmanes tuvieron que desembolsar más de 946 sueldos, que es el precio medio. Debemos indicar incluso que sólo en tres ocasiones la inversión fue menor a 100 sueldos. En definitiva, las familias islámicas que se acercaban al mercado de la tierra, debían desembolsar importantes sumas si pensamos en la escala de la microeconomía doméstica rural, lo que en el fondo nos habla de su capacidad de inversión y negocio. O dicho de modo más adecuado: estas cifras del mercado inmobiliario nos hablan de la aparición en las aljamas de un sector emprendedor local, de una élite interna que por sus negocios (mercado de aceite, actividades manufactureras, pequeño comercio minorista) consiguieron una mínima acumulación de capital que les permitió el acceso a tierras, heredades y huertos de alto precio. La aljama se jerarquizaba como lo hacían sus vecinos cristianos.

Si observamos el valor de las parcelas que vendieron los musulmanes en el mismo periodo citado, las cifras parcen confirmar la idea anterior: el valor medio de estos inmuebles que ponían en circulación era de 479 sueldos. La conclusión fácil de tal cálculo podría ser que los mudéjares compraban más caro que vendían, pero en realidad la gran cantidad de variables que influían en la venta de una parcela no nos permiten categorizar de esa forma. Lo que sí parece evidente es el elevado valor de muchos de los inmuebles que estaban en manos de este colectivo. De hecho, si sumamos tanto lo vendido como lo adquirido por éstos, el valor medio de las parcelas que llegaron a estar en sus manos ascendería a los 721 sueldos.

En cuanto a las formas de desembolso en estas compraventas de tierra, hemos observado que el crédito censal se convirtió en un método clave de pago aplazado. Pensemos que prácticamente el 35\% de las adquisiciones de parcelas llevadas a cabo por musulmanes, concluyen con un cargo de censal -un carregament- a favor del vendedor, lo que permitía ir pagando durante años el valor del inmueble. Algunos ejemplos resultan interesantes y modélicos: en 1485, Maymo Açet, de la morería de Cocentaina, compra al mercader de la misma villa Bartomeu Maiques, una parcela franca de olivar, situada en la partida contestana de Les Jovades, por el elevado precio de 960 sueldos, y para pagar la tercera parte de esa cantidad -300 sueldos-, Maymo carga un censal a favor de Maiques. De esta forma, el mercader recibirá anualmente 25 sueldos de Acet hasta que éste, o sus sucesores, entreguen el 
capital de 300 sueldos $^{43}$. Similar estrategia utilizó Mahomat Abib, comorante en la alquería de Fraga, cuando adquirió de Joan Pérez de Requena, pañero de Cocentaina, una heredad franca que incluía varias parcelas de olivar y dos corrales, y cuyo precio total ascendía a la elevada cifra de 3.000 sueldos; también para pagar una tercera parte del esa cantidad (ahora 1.050 sueldos), Abib cargó un censal a favor de Joan, por el que éste cobraría anualmente 87 sueldos y 6 dineros ${ }^{44}$.

Pensemos, no obstante, que estas prácticas de pago aplazado eran frecuentes tanto entre los musulmanes como entre los cristianos, y su uso no siempre implicaba de forma automática escasa solvencia o escasa capacidad económica del comprador. De hecho, entre las compraventas localizadas era también frecuente cuando el notario aporta la información- que la deuda que podía generar la adquisición del inmueble se cancelara en un periodo relativamente breve, de entre dos y cuatro años tras la firma de la escritura. Los casos de pago más dilatados documentados son los de Azmet Alicar, de Muro, que tarda cinco años en pagar los 1.733 sueldos que le costó una heredad en la partida de Les Capelles, en Muro, que compró al pelaire contestano Pere Fenollar; y el de Çaat Monçor, de la morería de Cocentaina, que tardó quince años en pagar la adquisición de dos parcelas francas (una de cereal y otra de olivar) por un total de 920 sueldos, que le compró al draper contestano Joan Pérez de Requena ${ }^{45}$. No obstante, este segundo caso tan dilatado constituye una excepción en todas las transacciones documentadas, y entendemos que no puede esgrimirse como ejemplo para justificar un exagerado nivel de endeudamiento del colectivo mudéjar. Por otro lado, y esto sí puede establecerse como norma, aquellos musulmanes que accedían a la compra de tierra poseían un cierto nivel económico dentro de la aljama, con una capacidad adquisitiva que les permitía hacer frente en poco tiempo a unas deudas que con frecuencia, y como hemos visto, rondaban siempre el millar de sueldos; además nos permite pensar que formaban parte frecuentemente $-\mathrm{y}$ eso nos lo ha confirmado el análisis prosopográfico- de su oligarquía interna. Los labradores más humildes, como ocurría entre sus vecinos cristianos, difícilmente podían acceder a este mercado de la tierra con precios tan elevados.

\section{LA ALJAMA, UN ESPACIO PLURAL: DUALISMOS SOCIOECONÓMICOS COMO CONCLUSIÓN}

Llegados a este punto, conviene que nos planteemos ciertas cuestiones clave: ¿quién podía acceder finalmente al mercado de la tierra?, ¿quién podía adquirir parcelas, huertos o casas? En definitiva, ¿cuántos compradores y vendedores

${ }^{43}$ APPV, notario Guillem Peris, 23810 (1485-IX-24). Como testigo de la venta y garante del comprador aparece Axer Ageig, herrero de la misma morería.

${ }^{44}$ APPV, notario Guillem Peris, 23815 (1492-II-6). La solvencia de Abib parece clara más pues en pocos meses el propio Abib compra al padre de Joan, Martí Pérez de Requena, diversos animales (tres vacas y un toro), por un precio de 233 sueldos, Idem, 1492-V-17.

${ }^{45}$ APPV 23.821, notario Guillem Peris (1498-II-1) y 23.386 (1491-XI-16). 
musulmanes han sido documentados, y qué supondría ello del total de la comunidad islámica rural? ¿Es muestra todo ello de la ya comentada jerarquización interna? Es muy importante constatar que en el total documental analizado, hemos llegado a localizar sólo a 51 musulmanes que intervienen en el mercado inmobiliario de esta área de Cocentaina y de sus alquerías vecinas (Fraga, Almudaina, Alcudia y Muro). Si esta zona estuvo poblada por unas 150-160 familias islámicas, el porcentaje de los que se acercaban a la mesa del notario para comprar o vender tierras sería alrededor de un tercio, o menor si cabe, por el hecho que nosotros contemplamos datos de un periodo de más de veinte años. Así, parece evidente que una parte importante de las familias musulmanas no tenía acceso a este mercado, que más bien resultaba privativo de los sectores islámicos «acomodados», que por su carácter emprendedor o por su posición de privilegio al frente de las aljamas habían conseguido cierta capacidad de negocio y ascenso económico entre los de su propia comunidad religiosa. Esto no hace sino confirmar la dualidad, como han marcado algunos autores, en la que vivía y se vertebraba la aljama, y sobre todo de los espacio rurales, con un amplio sector de campesinos sin tierra, en situación de dependencia, y un pequeño sector de propietarios con mejor capacidad de adaptación a las diferentes situaciones de presión y fiscalidad que marcaba la autoridad cristiana ${ }^{46}$.

Nuestros datos de compradores y vendedores confirman tal jerarquía interna. De la nómina de los 51 musulmanes que aparecen en los documentos de compraventa de inmuebles, sólo hay unos pocos (17) que intervienen más de una vez, el resto sólo ha sido localizado en una ocasión en el conjunto de los treinta años analizados. ¿Era esporádica la actuación de estos últimos? Tal vez sí, a la luz de la documentación conservada. Es decir, la mayoría de los musulmanes que accedían al mercado de la tierra o de otros inmuebles lo hacía pocas veces a lo largo de su vida, y posiblemente en casos de importante o de extrema necesidad, tanto para vender como para comprar, y en relación a la propia situación interna de la familia, a sus problemas financieros o a sus propios procesos de transmisión patrimonial. Los análisis prosopográficos nos han ayudado a tales afirmaciones: se trata en general de musulmanes de los que sólo hemos conocido una compra o venta inmobiliaria, pero de los que no hemos tenido ninguna noticia más en treinta años.

Sin embargo, había un pequeño grupo que frecuentaba la mesa notarial para sus diferentes negocios, y no sólo de tierras o casas, también de compraventa de productos agrícolas (cereales, aceite, sobre todo), incluso de ganado, lana o paños. De nuevo han sido las prosopografías las que nos han permitido descubrir este sector emprendedor local, esta auténtica élite de las aljamas. Familias como las Abib, Alafar, Cabe, Citbón, Collotí, Faraig, Mazuet o Zampar, formaron este grupo activo local en el área contestana durante los treinta años analizados, presentes en diferen-

${ }^{46}$ TORRÓ, Josep, “Vivir como cristianos...”, 11-40; VICIANO, Pau, Els peus que calciguen la terra..., 38-54. 
tes negocios y estrategias económicas. Son necesarios unos pocos ejemplos para ilustrar este particular perfil social dentro de las aljamas.

Cale Polopí fue tal vez el mercader más destacado de la morería de Cocentaina durante el periodo estudiado. Lo hemos documentado entre 1470 y 1500, y hemos llegado a conocer de este activo musulmán un total de 23 actuaciones ante notario. Su prosopografía nos indica que acudía al notario varias veces al año para gestionar sus negocios: en 1491 acudió al menos cuatro veces; tres durante 1495; y tres también en el año siguiente. A diferencia de buena parte de sus vecinos, Polopí frecuentaba la mesa notarial a causa de sus numerosos negocios en diversos sectores. A finales de 1470 lo encontramos por primera vez comprando 146 litros de aceite al mercader contestano Jaume Moltó; sólo un mes después vuelve al despecho de Guillem Peris para comprar otros 122 litros al mercader vecino Joan Juneda; posteriormente es localizado adquiriendo dos paños de lana por valor de 160 sueldos; compra seda por valor de 100 sueldos a un vecino de Oriola, ciudad situada 80 $\mathrm{km}$ al sur. Una noticia de 1487 nos habla de su capacidad económica y de su diversificación en los negocios: Polopí firma un contrato para abastecer de carne a la potente morería de Cocentaina durante un año, y vamos confirmando con documentos posteriores que es uno de los propietarios ganaderos más importantes de la zona; en febrero de 1488 vende a Jaume Aguilar, doncel de Valencia, 500 cabras a razón de 13 sueldos y 2 dineros por cabeza (6.583 sueldos es el valor del lote); pero de la misma manera que vende, compra ganado: en 1489 adquiere 165 cabras de Joan Miquel, vecino de Xixona, por un precio total de 2.520 sueldos; a principios de los noventa, llega a nombrar a la vez hasta cuatro procuradores-pastores distintos (todos ellos cristianos y vecinos de Bocairent i Castalla) para que cuiden su amplia cabaña. Entre los años 1492 y 1500 sigue con sus negocios ganaderos (le documentamos cinco ventas y dos adquisiciones) que le llevan incluso más allá de los límites de la comarca, a ciudades como Vila Joiosa o Elx. Su estrategia mercantil parece clara: actúa como agente redistribuidor de ganado en un amplio espacio supracomarcal. Pero los negocios de este activo mercader no se limitan al ganado, también el aceite y los cereales forman parte de su estrategia comercial: compra trigo, cebada y aceite en grandes cantidades que denotan una redistribución posterior. Por sólo citar las transacciones más importantes: en noviembre 1493 compra a Gabriel Bosch, mercader de Cocentaina, 25 cahíces de trigo (unos 5.000 litros) por un precio de 1.100 sueldos; en enero de 1500 compra a Onofre Calatayud, draper contestano, 100 arrobas de aceite (1.214 litros) por 700 sueldos. Esta intensa actividad mercantil con amplias exigencias de operaciones de almacenamiento y transporte le obligaba a contar con mano de obra auxiliar, por ello tenía en su casa un sirviente, Azmet, mancipium sive servicialem meum, como ocurría con los grandes mercaderes o artesanos emprendedores cristianos. De hecho, su volumen de negocio, su amplio mercado redistribuidor y la diversificación de su oferta, nos permite hablar de Cale Polopí como un auténtico emprendedor, y así lo manifiestan también sus relaciones con la élite mercantil y artesanal contestana, siendo tal vez el 
agente más importante de la aljama. Su patrimonio inmobiliario nos confirma dicho grado de riqueza: poseía al menos siete bancales, todos de propiedad franca, con su derecho a riego, situados en la huerta de Fraga, y valorados en un precio de 3.760 sueldos $^{47}$. Con tal currículum era lógico que Polopí fuera uno de los miembros más influyentes de la comunidad islámica, y que formara parte de su oligarquía: era miembro del consejo de ancianos, del conjunto de veteres, agareni et habitatores morarie predicte ville de Cocentayne, cuyo juramento ad Alquiblam Mahometi permitía la aprobación de los asuntos que concernían a la totalidad de la comunidad islámica.

Pero tal vez lo más interesante del ejemplo de Cale Polopí es que éste no era único. Parecido volumen de negocio y objetivo empresarial lo encontramos también en otros agentes de la aljama. Çaat Maymo (1471-1504), que aparece como «tendero» en los documentos notariales, desarrolla similares negocios tanto en el mercado de aceite como de ganado. Sus numerosas compras de aceite documentadas superan siempre los 900 litros. Adquiere también ganado superando siempre las 160 cabezas, y se asocia con frecuencia a artesanos pañeros cristianos para ese fin: en 1481, junto al pelaire contestano Bernat Figuerola, compra 182 cabezas por 1.183 sueldos; la importancia de su negocio dentro y fuera de la aljama se confirma porque es propietario de un taller (operatorium sive obrador) en Cocentaina, en la zona privilegiada de la Plaza del Mercado, donde se concentran numerosos talleres de importantes artesanos cristianos de la villa. En 1500 vende una parte de este taller al pelaire contestano Pasqual Sempere por un precio de 110 sueldos. El propietario del dominio directo del taller es el conde de Cocentaina, a quien se le debe pagar anualmente un censo enfitéutico de 20 sueldos. En cuanto a su patrimonio sabemos además que poseía un huerto tapiado, situado en el Pla de la Font, con su derecho a riego, valorado en unos 1.000 sueldos, y una parcela de terra campa, franca, situada junto al molino pañero de Cocentaina. Su competencia en los negocios y su prestigio le llevó a ser nombrado, por dos veces, los años 1495 y 1504, procurador de la aljama contestana, la primera para cargar un censal por valor de 1.260 sueldos, y la segunda para adquirir cereal por valor de 20.000 sueldos destinado a las comunidades islámicas de Cocentaina y Muro.

Alí Zampar (1470-1491) fue otro de los operadores importantes del área contestana. Compra diversos paños de calidad y alto precio (con valores siempre superiores a 200 sueldos por paño); también aceite en transacciones elevadas (superiores a los 1.600 litros), así como ganado (por ejemplo, vende a Alfons Beneito, agricultor de Bocairent, 563 cabezas de ganado lanar, y cinco mulas, todo por un precio de 4.128 sueldos); se dedicó, también, como en este ejemplo, a la venta de animales de tiro (con un precio medio de 270 sueldos). En cuanto a su patrimonio,

\footnotetext{
${ }^{47}$ Adquirió los inmuebles de Bernat Puig, agricultor de Cocentaina, en diciembre de 1491. Sobre ésta y todas las referencias documentales anteriores y las que ofrecemos a continuación, LLIBRER, José Antonio, Industria textil y crecimiento regional..., vol. II, 304-325. Todos los datos forman parte de las prosopografías que han sido elaboradas en ese proyecto doctoral.
} 
ha sido localizado adquiriendo tres inmuebles: en 1470, un huerto, con su derecho a riego, por el que pagó 900 sueldos; en 1482 compró un moreral por 600 sueldos; y en 1491 adquirió un olivar en regadío por 120 sueldos. Llegó finalmente, a partir de 1487, a ser alamín de la aljama, lo que le llevó a contactar con el conde de Cocentaina para la recaudación de sus rentas.

Azmet Alicar (1471-1500), de Muro, se dedicó a la redistribución de aceite (con compras elevadas, la mayor documentada fue de 5.422 litros), pero también de lana entre los pañeros cristianos de Cocentaina (lo que nos permite intuir inversiones ganaderas). Su relación con los artesanos cristianos le llevó a adquirir una heredad con casa, en Muro, al pelaire Pere Fenollar, por un precio de1.733 sueldos. También conocemos datos de otros miembros de este activo linaje islámico, como de Axer Alicar, uno de los pocos sastres musulmanes documentados, o de Mahomat, participante en el mercado de aceite y propietario de dos bancales en la huerta de Muro (valorados en 960 sueldos).

También los tres hermanos Borix (1470-1498), otro influyente linaje local, se dedicaron a la redistribución de paños. Azmet y Mahomat compraron conjuntamente seis paños en año y medio. Se dedicaban paralelamente a la distribución de cereales (en una única compra adquirieron 1.200 litros de trigo) y a la de aceite (les documentamos cuatro adquisiciones con precio medio de 620 sueldos), siendo en este último negocio donde su inversión fue mayor, por la toma en arrendamiento de una almazara en Cocentaina (del pelaire Bernat Ripoll) por tiempo de un año -1498-, y 607 litros de aceite.

Acén Citbón (1471-1502) también invirtió en la producción oleícola mediante una doble estrategia: el control de almazaras y el dominio de parcelas de olivar. En 1471 compró al pelaire contestano Francesc Ripoll, el dominio útil de una casa almazara con todos sus instrumentos para la molienda, y con un patio o solar contiguo por 500 sueldos; el inmueble estaba obligado a un censo enfitéutico de 2 sueldos y 6 dineros. Por otro lado, en 1491 compró al pañero contestano Bartomeu Bodí, una parcela de terra campa y olivar, en regadío, en la partida de Les Jovades, por 829 sueldos; cuatro años después tomó en arrendamiento una parcela de olivar, situada en la misma partida anterior, propiedad de Gabriel Bosch, apotecari de Cocentaina, por un período de cuatro años, y un elevado precio de 140 sueldos anuales. También arrendó la alfalfa de la heredad de Pere Martí, por un año y 140 sueldos. Ha sido documentado además comprando cuatro paños de lana, en diversos años, con precio medio de 300 sueldos.

Todos estos ejemplos, y algunos otros que podríamos añadir (como el del linaje de los Cabe, Ubaydal o Xativí, con características parecidas a los anteriores) nos ofrecen un perfil social, y económico, muy concreto en estas aljamas rurales. Se trata de pequeños hombres de negocio, de pequeños empresarios, que supieron aprovechar su propio mercado interno, es decir, el mercado musulmán que conformaban la gran cantidad de aljamas de estos valles de interior. Era hacia esas comunidades islámicas hacia donde estos mercaderes o tenderos llevaban sus pro- 
ductos (aceite, cereales, tejidos) que habían adquirido en grandes cantidades a los cristianos. El secreto de esta pequeña elite local islámica residía aquí: comprar al por mayor a los cristianos y vender al por menor a sus vecinos o a otros musulmanes de aljamas más alejadas. En ocasiones, como hemos visto, este grupo emprendedor podía desarrollar una producción propia (así nos lo indican sus propias parcelas de cereal, de olivar o sus almazaras) para después vender estos amplios excedentes. Es cierto que las ventas al por menor entre musulmanes pocas veces aparecen en la documentación (entre otras razones, por evitar el gasto de gestión notarial), pero se intuyen con toda claridad a juzgar, primero, por los amplios volúmenes de las transacciones conservadas y por la propia particularidad y limitación de buena parte de los campesinos musulmanes, ya conocida y estudiada.

En efecto, y esto nos remite de nuevo a la idea de una marcada dualidad socioeconómica en las aljamas, para muchos de estos vecinos, de condición sin duda más humilde, acceder a una gran compra de aceite o de cereales de cientos de sueldos era enormemente difícil, como también lo era -y así lo hemos visto- acceder a más tierras tanto en arriendo como en otras formas de gestión. Estos campesinos, y estas familias de clase inferior, sobrevivían en exclusiva con el trabajo de la tierra de sus limitadas explotaciones, en aquellos casos en que hubieran accedido a ciertas parcelas; pero en muchos otros casos, sin posibilidades de acceder a parcelas propias, la supervivencia pasaba por el trabajo en heredades de otros vecinos, esencialmente cristianos, englobando una amplia masa de campesinos jornaleros sin tierra. En Cocentaina, importante villa industrial, con una poderosa comunidad de artesanos dedicados a la producción de paños de lana y seda, las posibilidades para estos jornaleros agrícolas eran abundantes en las numerosas parcelas que muchos tejedores, pelaires, tundidores, tintoreros o pañeros cristianos poseían, como hemos podido documentar y contabilizar a través de los análisis prospográificos realizados entre este amplio colectivo manufacturero ${ }^{48}$.

Con todo, esta numerosa capa de labradores musulmanes desposeídos ha dejado pocos rasgos en la documentación dado que pocas veces firmaban contratos de trabajo o cualquier otro tipo de acuerdo con los propietarios. Sin embargo alguna vez el pago de tales trabajos asalariados ha llegado a la mesa del notario. Es el caso, por ejemplo, de Mahomat Xumilla, agareno de la morería de Xàtiva, que acude al despacho notarial de Guillem Peris para reconocer que Francesc d'Albinyana, agricultor de Canals, le ha pagado 200 sueldos que le debía por distintos trabajos en una heredad de su propiedad situada en Montesa (a $18 \mathrm{~km}$ de Xàtiva), ratione et causa treballs quibus feci et prestari in hereditate vestra sita in termino ville de Muntesia ${ }^{49}$. La cantidad, más bien elevada, exigió el paso por el notario, que pocas veces ocurría. En realidad, podemos conocer a este sector de campesinos musulmanes sin tierra gracias también a los análisis prosopográficos por el hecho que su

\footnotetext{
${ }^{48}$ LLIBRER, José Antonio, Industria textil y crecimiento regional..., vol. II, 15-335.

${ }^{49}$ APPV, 23.803, notario Guillem Peris (1478-V-14).
} 
presencia en las fuentes es muy esporádica en un dilatado periodo de tiempo. En efecto, para Cocentaina y sus alquerías conocemos los nombres de muchos musulmanes que acudieron una sola vez al notario en más de treinta años, y que se acercaron a su mesa para pequeñas compraventas o para saldar alguna deuda. Estos conformarían sin duda ese grupo de humildes campesinos. Es el caso, con toda probabilidad, de Abrahim Carbó, residente en la morería de Cocentaina, del que sabemos únicamente que compró 10 arrobas de aceite a Joan Juneda, mercader contestano, por sólo 46 sueldos. O el de Mahomat Fat, de Fraga, que acudió a Cocentaina para comprar trigo por 46 sueldos. O el de Alí Fucell, que compró, junto a Acén Muça, dacsa por valor de 60 sueldos. O el de Mahomat Ayola, que acude al notario para reconocer que debe el precio de un pequeño paño, un drap morich. También el de Acén Muça i Çaat Roho que confiesan ante notario deber 140 sueldos por un fragmento de paño que compraron conjuntamente ${ }^{50}$. En todos los casos, y en otros muchos, su presencia ante notario es esporádica, sólo una noticia en más de treinta años, por lo tanto, escasa capacidad de producción, escasas posibilidades de negocio, fuertes posibilidades de endeudamiento... Y muchas veces son deudas lo único que reconocen ante notario: Abrahim Gordomaç y su esposa confiesan deber a Joan Domingues 147 sueldos por un préstamo que éste les hizo, los quals deure li confessaren per préstech. Ayola Cachet reconoció parecida deuda -100 sueldospor idéntico concepto ${ }^{51}$.

Hasta tal punto el nivel de endeudamiento y limitación económica era elevado para un amplio sector de la comunidad islámica contestana, que el propio conde, Joan Roís de Corella, decidió en 1482 reducir el impuesto del morabatí a muchos vecinos de su morería, de forma que sólo pagaran un sueldo anual, porque, según afirmaba el mismo conde, en la present nostra moreria huy se atroben moltes persones miserables e pobres, les quals ab menys treball e dan, cascun any, pagarien lo dret del morabatís

Pero en el otro extremo de la aljama, y esto es lo que hemos querido mostrar y analizar en este artículo, encontramos un conjunto de emprendedores mudéjares que fueron capaces de invertir en nuevas tierras, de vender sus excedentes en los mercados locales o comarcales, llegando incluso a generar pequeñas empresas de distribución o intercambio de distintos productos (ganado, cereales, aceite, lana, paños) entre las aljamas vecinas. La venta de excedentes en los mercados locales o comarcales nos indica en buena lógica que muchos mudéjares producían por encima del nivel de subsistencia, lo que era posible, en parte, por la adquisición o arrendamiento de tierras. El perfil sociolaboral de muchos de estos mudéjares emprendedores, que hemos intentado trazar, combinaba el trabajo agrícola, o arte-

\footnotetext{
${ }^{50}$ Es importante constatar que todos estos documentos citados son reconocimientos de deuda por parte de los musulmanes.

${ }^{51}$ Todas las referencias prosopográficas y documentales en, LLIBRER, José Antonio, Industria textil y crecimiento regional..., vol. II, 303-326.

${ }^{52}$ APPV, 23.807, notario Guillem Peris (1482-V-24).
} 
sanal, con el comercio minorista entre los miembros de sus propias comunidades, e incluso con la responsabilidad en la aljama mediante la ocupación de sus cargos clave. En definitiva hablamos de un colectivo que no hace sino mostrar los procesos de jerarquización socioeconómica que se estaban generando en el seno de las comunidades islámicas donde convivían, junto a un sector de humildes campesinos, otro grupo emprendedor que producía excedentes, ampliaba negocios y mejoraba su capacidad económica y su prestigio.

\section{APÉNDICE}

\section{CENSO PROSOPOGRÀFICO DE LOS MUSULMANES DE COCENTAINA Y SU TÉRMINO (1470-1505)}

Fuente: LLIBRER, José Antonio, Industria textil,... vol. II, 303-325 53

ABDULAZIZ, Azmet (1482), carbonero de la aljama de Cocentaina ${ }^{54}$ ABENCHAYDA, Abrahim (1471), de Cocentaina ABENHIELL, Yaye (1471), de Cocentaina.

ABENLOP, Çaat (1496), maestro albañil de Cocentaina ABENMELICH, Azmet (1474), de Cocentaina ABIB, Mahomat (1481-1492), de Cocentaina, y comorante en Fraga (1487) ABLACH, Çaat (1470), albardero de Cocentania ABLAI, Galip (1494), cintero de Cocentaina ABOAMIT, Abdallà (1470-1491), albardero de Cocentaina ABOAMIT, Axer (1480-1485), albardero de Cocentaina ABOAMIT, Mahomat (1473), albardero de Cocentaina. ABORRAZ, Abrahim (1480), alias Cudori, ollero de Cocentaina ABULHAZÉN, Abrahim (1474), de Cocentaina ACEN, Çaat (1472), de Cocentaina AÇET, Maymo (1485), de Cocentaina AGEIG, Axer (1485), herrero de Cocentaina ALAFAR, Çaat (1482), sastre vecino de Muro ALAFAR, Ucey (1474-1480), de Muro ALAP, Gualip (1487-1492), cintero de Cocentaina ALATAR, Abrahim (1474-1498) alias Negrello, jabonero de Cocentaina

\footnotetext{
${ }^{53}$ La base documental utilizada para la elaboración de este censo corresponde al conjunto tanto de protocolos notariales como de Manuals de Consell y libros de la Cort de Justícia en la cronología citada que se conservan en el Archivo Municipal de Cocentaina y en Archivo de Protocolos del Colegio del Corpus Christi o del Patriarca, de Valencia, y que son inventariados en nuestro proyecto doctoral.

${ }^{54}$ Entre paréntesis, el año o años en que dicho individuo ha sido documentado. En todos los casos hemos respetado la grafía original de la documentación.
} 
ALBARAXÍ, Azmet (1471), de Fraga

ALBUBAHAR, Cilim (1474), de Catamarruc

ALBURUCH, Abdulaziz (1471), jabonero de Cocentaina

ALCADÍ, Abrahim (1471-1493), cintero de Cocentaina

ALCADÍ, Axer (1480-1494), tendero de Cocentaina

ALDÁN, Alí (1481), comorante en l’Alcúdia

ALDÁN, Azmet (1487), de Cocentaina

ALEXANDRÍ, Mahomat (1480), trajinero de Cocentaina

ALFAQUÍ, Mahomat (1480), cantarero de Cocentaina

ALFARQUI, Azmet (1491), alias Petrayre, de Cocenaina

ALHUAQUIL, Mahomat (1474-1479), de Almudaina

ALICAR, Azmet (1471-1500), alias Miges, de Muro, hijo de Mahomat

ALICAR, Axer (1498), sastre comorante en Muro

ALICAT, Abraham (1498), panadero de Cocentaina

ALICAR, Mahomat (1494), de Muro

ALIOL, Çaat (1485-1500), de Cocentaina

ALMENARÍ, Cilim (1479-1489), tendero comorante en Cocentaina

ARAY, Azmet (1474), de Muro

ASQUER, Abrahim (1479), de Cocentaina

ATAP, Azmet (1480), de Cocentaina.

AXEIX, Azmet (1491), herrero de Cocentaina

AYET, Acén (1470/1471), alfaquí de Benilloba

AYOLA, Mahomat (1493), de Cocentaina

BAQUA, Mahomat (1473), de Fageca

BARBARROJA, Alí (1493), de Cocentaina, hijo de Cilim

BARBARROJA, Azmet (1471-1472), trajinero de Cocentaina

BARBARROJA, Cilim (1493), de Cocentaina, padre de Alí

BARBARROJA, Yucef (1470/1473), trajinero de Cocentaina

BEN YUCEF, Çaat (1487), alias Faqui, agareno de Muro

BORIX / ABORIX, Azmet (1470/1472) de Cocentaina

BORIX / ABORIX, Mahomat (1470/1479), tendero de Cocentaina

BORIX / ABORIX, Yucef (1471/1472), de Cocentaina. Hermano de Mahomat

BUXIRQUÍ, Çaat (1498), barbero de Cocentaina

CABE, Abrahim (1488), de Cocentaina

CABE, Çaat (1473-1485), barbero de Benufit. Tendero en Cocentaina (1480)

CABE, Borayham (1492), carpintero comorante en Cocentaina

CABE, Cilim (1491-1496), carpintero de Xàtiva y comorante en Cocentaina

CABE, Mahomat (1472-1500), albañil de Cocentaina

CABE, Yaye (1470-1471), de Muro

CABRERA, Azmet (1474), de Cocentaina

CACHOLA, Abrahim (1481), de Cocentaina

CADILLA, Abrahim (1485-1493), de Cocentina 
CALE, Azmet (1474), de Cocentaina

CALE, Mahomat (1479), podador de Cocentaina

CARBO, Abrahim (1471), de Cocentaina

CASTALLÍ, Çaat (1470), de Cocentaina

CASTALLÍ, Yucef (1500), alpargatero de Cocentaina

CITBON, Acén (1471-1502), de Cocentaina

COLLOTÍ, Alí (1479), de Fraga, hijo de Mahomat

COLLOTÍ, Mahomat (1479), de Cocentaina

COLLOTÍ, Palluix (1481), de Fraga

CONFRIDI, Çaat (1471-1491), de Cocentaina

CUDORI, Ayet (1485-1495), alfarero de Cocentaina

CHECLIMA, Cilim (1471-1494), de Cocentaina

DINDAL, Çaat (1480-1487), fabricante de tejas y albañil de Cocentaina

FALIFA, Bolaix (1471), de Cocentaina

FAQUÍ, Azmet (1471), comorante en Cocentaina

FARAGO, Azmet (1474), de Almudaina

FARAGO, Yucef (1474), de Almudaina

FARAIG, Azmet (1474), comorante en Muro

FARAIG, Mahomat (1474), comorante en Muro. Hermano del anterior

FAT, Axer (1480), molinero de la alquería de Alcoceret

FAT, Mahomat (1471), de Fraga

FRANGELL, Mahomat (1493), ganadero de Cocentaina

FUCELL, Alí (1473), de Cocentaina

GANIM, Azmet (1479), de Beniarjó

GIBER, Abrahim (1496), de Fraga

GIBER, Acén (1480), de Cocentaina

GIBER, Çaat (1474), de Cocentaina

GIBER, Mahomat (1496), de Fraga, hermano de Abrahim

HABEIX, Azmet (1494), herrero comorante en Cocentaina

HALAF, Alí (1474), de Almudaina

ILLEL, Azmet (1480), de Cocentaina

ILLEL, Yaye (1482), de Cocentaina

LOPPO, Maymo (1472), pastor de Muro

LOPPO, Palluix (1494), de Muro

MALLORQUÍ, Alí (1473-1471), herrero de Cocentaina

MAROP, Çaat (1471-1473), alias requero, de Cocentaina

MARCHOP, Çaat (1487), de Cocentaina

MAYMO, Çaat (1471-1504) tendero y trajinero de Cocentaina

MAZUET, Çaat (1481), de Cocentaina.

MAZUET, Mahomat (1472), de Cocentaina

MAZUET, Yaye (1473), pastor de Cocentaina

MERLI, Atap (1479), alamín de Cocentaina 
MECLI, Ucey (1493), de Muro

MONÇOR, Çaat (1491) alias Mengapà, comorante en Cocentaina

MORIT, Cale (1473), de la Vall de Gallinera

MUÇA, Acén (1474). de Cocentaina

NAGA, Azmet (1469-1500), herrero de Cocentaina

PACHI, Azmet (1474), herrero de Cocentaina

POLET, Mahomat (1471), calcetero de Cocentaina

POLOPI, Cale (1470-1500), mercader de Cocentaina

QUESALLÍ, Yaye (1492), alamín de Fraga

RAGA, Azmet (1482), de Cocentaina

RAMI, Mahomat (1495) alias Dolet, pastor de Muro

RAMI, Yaye (1474), de Catamarruc

RASCONI, Çaat (1473), de Cocentaina

ROGET, Çaat (1474), de Fraga

ROHO, Çaat (1474), de Cocentaina

RUFÀ, Alí (1471-1474), aceitero de Cocentaina

SUCEY, Abrahim (1470), de Alcoleja

UBAYDAL, Abrahim (1492), yesero de Cocentaina

UBAYDAL, Alí (1471), sastre de Cocentaina

UBAYDAL, Mahomat (1492) alias Cale, yesero de Coentaina

ULEY, Çaat (1493) alias Magraner, de Cocentaina

USMEN, Azmet (1474), de Catamarruc

XATET, Abrahim (1479), de Cocentaina

XATIVÍ, Çaat (1489-1496), herrero comorante en Cocentaina

XATIVÍ, Mahomat (1472-1498), de Cocentaina, hijo de Çaat

XATXÍ, Azmet (1491), herrero comorante en Cocentaina

YAYE, Çaat (1471-1474), de Cocentaina

ZAMPAR, Alí (1470-1491), tendero de Cocentaina

ZAMPAR, Çaat (1491), de Cocentaina, hijo de Alí

ZUBEYDA, Bolaix (1491), comorante en Cocentaina 